\title{
Radioecological assessments of the lodine working group of IAEA's EMRAS programme: Presentation of input data and analysis of results of the prague scenario
}

\author{
M. Bartusková ${ }^{1}$, I. Malátová ${ }^{2}$, V. Berkovskyy ${ }^{3}$, P. Krajewski ${ }^{4}$, M. Ammann ${ }^{5}$, \\ V. Filistovic ${ }^{6}$, T. Homma ${ }^{7}$, J. Horyna ${ }^{8}$, B. Kanyár ${ }^{9}$, T. Nedveckaite ${ }^{6}$, \\ O. Vlasov ${ }^{10}$ and I. Zvonova ${ }^{11}$ \\ ${ }^{1}$ NRPI, Ostrava, Czech Republic \\ ${ }^{2} \mathrm{NRPI}$, Prague, Czech Republic \\ ${ }^{3}$ IAEA, Vienna, Austria \\ ${ }^{4}$ CLOR, Warsaw, Poland \\ ${ }^{5}$ STUK, Helsinki, Finland \\ ${ }^{6}$ Institute of Physics, Vilnius, Lithuania \\ ${ }^{7}$ Japan Atomic Energy Agency, Ibaraki-ken, Japan \\ ${ }^{8}$ SONS, Prague, Czech Republic \\ ${ }^{9}$ University of Pannonia, Veszprem, Hungary \\ ${ }^{10}$ MRRC, RAMS, Obninsk, Russian Federation \\ ${ }^{11}$ IRH, St. Petersburg, Russian Federation
}

\begin{abstract}
In 2003 IAEA launched the EMRAS Programme aiming at evaluating the predictive power of radiological models. The programme continued work of previous international radioecological modelling programmes and comprised several working groups focusing on different aspects of environmental modelling. The Iodine Working Group reassessed the impact of the release of ${ }^{131} \mathrm{I}$ during the Chernobyl accident with the aim of comparing model predictions with environmental data and inter-comparing the model predictions. Measurement data and detailed geographic and demographic descriptions were available for three regions: Plavsk, Warsaw and Prague. As for the Prague Scenario, milk supply regions of three big dairies were chosen for the model validation. Apart from geographic, demographic and agricultural descriptions (e.g. gathering regions of the dairies, feeding regime), the modellers were provided with information on the weather conditions and measurement data of iodine contamination. The most important peculiarities of Prague Scenario were keeping milk cattle in sheds and a special feeding regime during May 1986. The modellers were asked to assess the ${ }^{131}$ I content in the thyroid of the local population and the resulting dose. The assessments were compared with measurement data. The results of these model calculations and their comparison with experimental data are presented.
\end{abstract}

\section{INTRODUCTION}

The activities of the IAEA EMRAS ${ }^{131}$ I Working Group (IWG) were targeted at evaluating the predictive capability of environmental models, particularly in relation to assessing the thyroid exposure due to inhalation and ingestion of ${ }^{131} \mathrm{I}$. Environmental monitoring data from the ${ }^{131} \mathrm{I}$ pathway following the Chernobyl accident were presented for model validation. Three scenarios, each of them with different specifics, were assessed: Plavsk, Warsaw and Prague. The main aim of the Plavsk Scenario was to validate the models with respect to dose reconstruction in cases when ${ }^{137} \mathrm{Cs}$ is used as a tracer for the estimation of the deposition of ${ }^{131} \mathrm{I}$. Two end points were provided: ${ }^{131} \mathrm{I}$ concentration in milk and ${ }^{131}$ I in thyroid of humans. The Warsaw Scenario, on the other hand, allowed to assess the influence of countermeasures consisting of administration of stable iodine to children and teenagers up to 16 years of age, putting grazing dairy cows on stored feed, followed by the ban of potentially contaminated milk, milk products and leafy vegetables. Finally, the Prague Scenario was focused on several aspects of the internal ${ }^{131}$ I dose evaluation in a case when a special cow feeding regime was applied. 
Prague covers an area $496 \mathrm{~km}^{2}$, and the first signals of a contaminated plume over that territory were detected during the night from 29 to 30 April 1986. Another two passages of contaminated air through that territory were observed: from 3 to 4 May' and on 7 May 1986. These radioactive clouds resulted in locally elevated levels of ${ }^{137} \mathrm{Cs}$ in soil and, as expected, higher ${ }^{131} \mathrm{I}$ deposition in the same locations.

\section{MATERIALS AND METHODS (INPUT DATA FOR PRAGUE SCENARIO)}

The gathering regions of three big dairies were chosen for the evaluation exercise. Maps of the gathering regions of the Prague-Troja, Prague-Kyje and Benešov dairies are shown in figure 1a). The Figure also shows the sampling points of soil in which the fall-out of ${ }^{137} \mathrm{Cs}$ and ${ }^{131} \mathrm{I}$ was determined. Figure $1 \mathrm{~b}$ ) shows the location of the region of interest in the Czech Republic. Two dairies were in the city area of Prague, the third one was chosen from a nearby district with higher ${ }^{137} \mathrm{Cs}$ deposition.

The modellers were supplied with geographical and demographical information, and with data on the, weather conditions during cloud passage (wind directions, rain and temperature), and on agriculture and food consumption. In addition, measurement data of the ${ }^{131}$ I concentration in air at three stations in Prague were provided. At the Prague-Libeò station, aerosol and gaseous forms of iodine were measured separately [1,2] (see in figure 2). In the whole Central Bohemia region, 195 soil samples were collected and measured for their ${ }^{137} \mathrm{Cs}$ contamination. Only in some of them also the ${ }^{131} \mathrm{I}$ contamination could be measured when a nation-wide survey was performed on June $16^{\text {th }}$ and $17^{\text {th }} 1986$. Some measurements exist from May $25^{\text {th }} 1986$; however, they covered only eastern part of Benešov district.

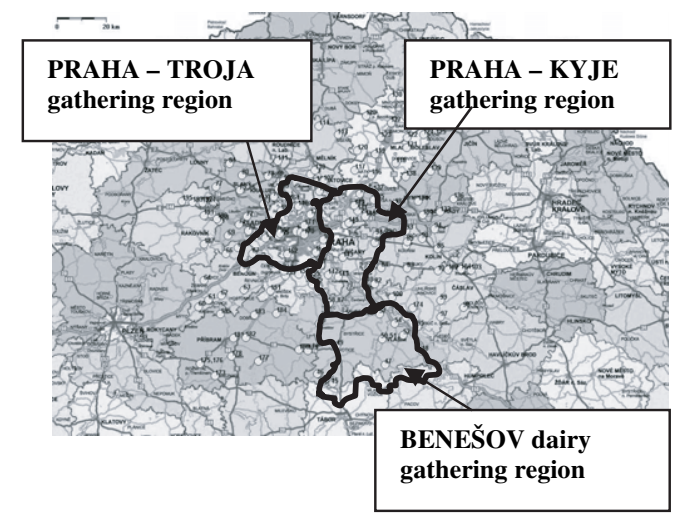

a)

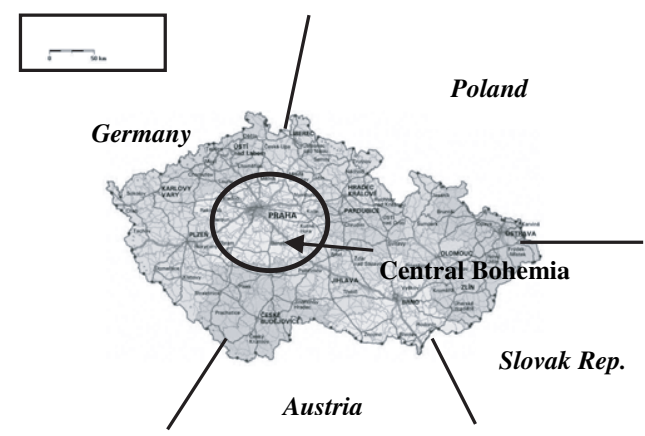

b)

Figure 1. a) Gathering regions of three chosen dairies and soil sampling points in these gathering regions b) Location of region of interest in the Czech Republic.

Individual modellers had to use their expert judgment as to the fall-out of iodine for the places in which not enough experimental data were collected - it was possible either to derive the data from the nearest aerosol station or to make use of the measurement of fall-out of ${ }^{137} \mathrm{Cs}$ for which more data existed.

The most important feature of the Prague Scenario was keeping the dairy cows in sheds and on a special feeding regime during May 1986. However, it was difficult to give modellers exact data about this countermeasure, as it was not publicly announced (there was a centrally governed communist regime in the then Czechoslovakia); this recommendation was given on May $6^{\text {th }}$ to $8^{\text {th }}$ through official channels only. Milk consumption with activity of ${ }^{131} \mathrm{I}>1000 \mathrm{~Bq} \cdot \mathrm{L}^{-1}$ was banned. In addition to this, the beginning to mid May usually is the transition time from dry to fresh fodder, so it is problematic to 


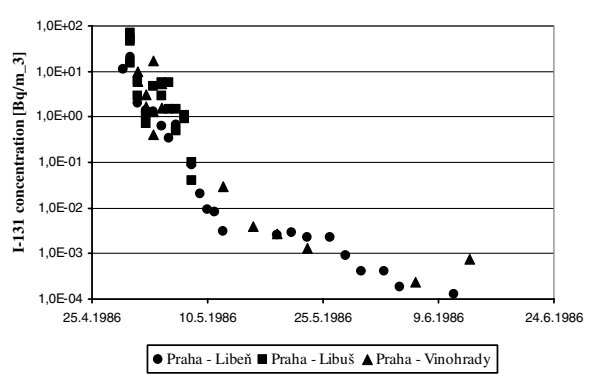

Figure 2. ${ }^{131}$ I concentrations in aerosols, collected in the three parts of Prague, April $29^{\text {th }}-$ July $13^{\text {th }} 1986$.

define quantitatively fractions of fresh and dry fodder in dependence on time even in a normal situation. It is nearly impossible to reconstruct how individual collective farms respected internal instructions because most of them do not exist any more or have been transformed to private sector. Therefore, it was decided that modellers would calculate two extreme cases - when no fresh fodder was consumed by cattle and when cattle were in pasture from the beginning of the accident; for both cases ${ }^{131}$ I milk concentration and thyroid doses had to be calculated.

Modellers were supplied with data about the consumption of milk and vegetables; other products were not important from the point of view of doses from ${ }^{131} \mathrm{I}$. Age dependence of consumption was used from CB Scenario of the VAMP project [3]. However, the milk consumption was given in "milk equivalent" of milk products, though the activity of ${ }^{131}$ I was, because of radioactive decay, much lower in some of the products than in milk. Modellers had to use their expert judgment, mostly based on the experience made in their own countries after the Chernobyl accident.

Eight different models were used for calculations of ${ }^{131} \mathrm{I}$ activity concentrations in milk and for estimation of the ${ }^{131}$ I activity in thyroid. An overview of the models is presented in table 1.

Table 1. Overview of the models.

\begin{tabular}{|c|c|c|c|}
\hline Model & Participant Name & Country & Organization \\
\hline LIETDOS & T. Nedveckaite, V. Filistovic & Lithuania & Institute of Physics \\
\hline OSCAAR & T. Homma & Japan & $\begin{array}{c}\text { Japan Atomic Energy Agency } \\
\text { (JAEA) }\end{array}$ \\
\hline UniVes & B. Kanyár & Hungary & $\begin{array}{c}\text { University of Pannonia } \\
\text { (former University of Veszprém) }\end{array}$ \\
\hline CLRP & P. Krajewski & Poland & $\begin{array}{l}\text { Central Laboratory for Radiological } \\
\text { Protection }\end{array}$ \\
\hline Ecosys-87 & M. Ammann & Finland & $\begin{array}{c}\text { Radiation \& Nuclear Safety Authority } \\
\text { (STUK) }\end{array}$ \\
\hline CLIMRAD & O. Vlasov & $\begin{array}{c}\text { Russian } \\
\text { Federation }\end{array}$ & Medical Radiological Research Center \\
\hline IRH-model & Irina Zvonova & $\begin{array}{l}\text { Russian } \\
\text { Federation }\end{array}$ & Institute of Radiation Hygiene \\
\hline SCHRAADLO - T & Jan Horyna & $\begin{array}{c}\text { Czech } \\
\text { Republic }\end{array}$ & State Office for Nuclear Safety \\
\hline
\end{tabular}

\section{RESULTS AND DISCUSSION}

In figure 3 examples of results of model calculations (best estimates) in comparison with measured data for Praha-Kyje and Benesov dairies are given [4].

The underestimated predictions for the first days of May are caused by the assumption that the cattle were kept in stables and inhalation was the only way of intake of iodine. Some modellers assumed 
different degrees of contamination of stored feedstuff through ventilation, what caused much lower iodine intake than stay on the pasture. For the Benešov dairy all modellers calculated higher values than measured data. It could be caused by the fact that the cattle were kept longer time on stored feedstuff because of lack of fresh fodder in the hilly area.

End-points for comparison with model calculations were ${ }^{131}$ I milk concentrations from the three dairies and ${ }^{131}$ I activity in thyroid of Prague inhabitants. It was not possible to assign individuals to consumption from a certain dairy; mixed consumption was probable. Results of model calculations for adult Prague inhabitants together with measured data are presented in figure 4. For the period before May $11^{\text {th }} 1986$ all models seem to underestimate measured values; this is probably due to measured data which came from whole body counting and measured values were probably influenced by surface contamination of hair and beards. For the later times, the agreement between all models and observed data is fairly good.

Modellers had to calculate doses to thyroid of age groups 1, 5, 10 years and of adults. For illustration, the thyroid doses in the adult population are given in table 2. The pattern of the dose distribution in all age groups was similar. With the exception of the three model calculations (OSCAAR, UniVes and CLRP) that assumed feeding of cows with uncontaminated feedstuff all the time, the results are within an order of magnitude. Similar factors of uncertainty have been reported by other authors dealing with post Chernobyl ${ }^{131}$ I dose reconstructions in the most contaminated areas of Belarus and Ukraine [5, 6].
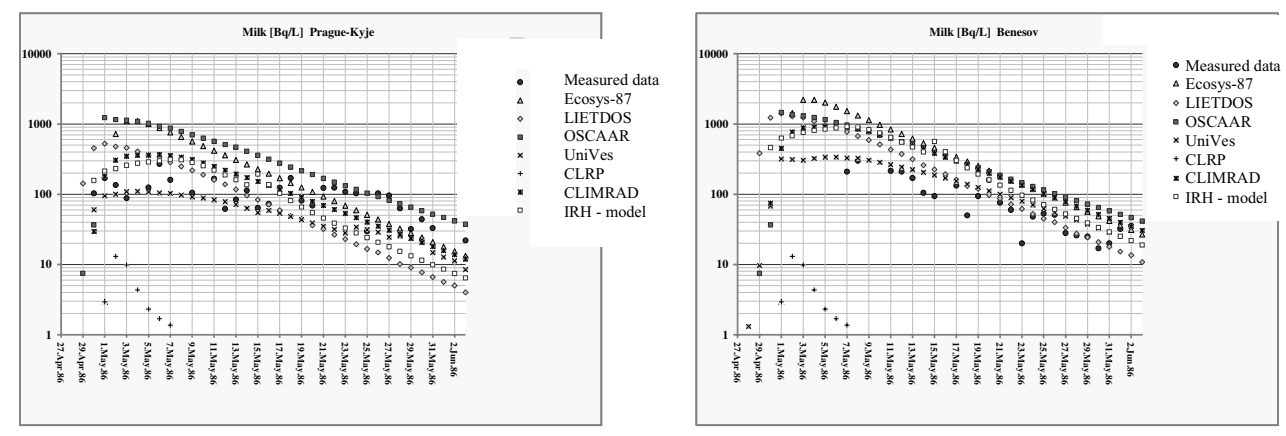

Figure 3. Results of calculations of ${ }^{131}$ I activity concentration in milk for the Prague-Kyje and Benešov dairies in comparison with measured data.

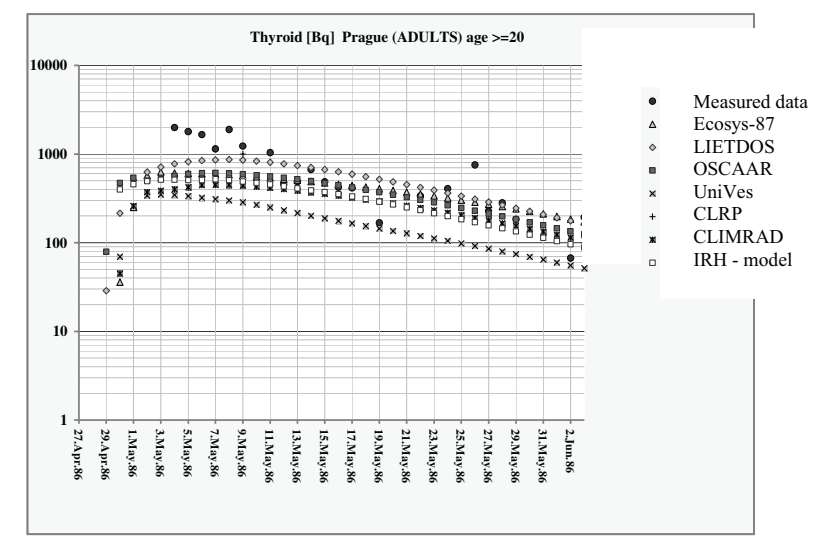

Figure 4. Estimations of ${ }^{131} \mathrm{I}$ activity in thyroid $[\mathrm{Bq}]$ for adult Prague inhabitants in comparison with measured data. 
Table 2. Inhalation and ingestion thyroid doses for adult inhabitants of Prague, calculated by models.

\begin{tabular}{|c|c|c|c|c|c|}
\hline \multirow{2}{*}{ Model } & \multicolumn{3}{|c|}{ Inhalation doses [mSv] } & \multicolumn{2}{c|}{ Ingestion doses [mSv] } \\
\cline { 2 - 6 } & $\begin{array}{c}8 \mathrm{~h} \text { in } \\
\text { building }\end{array}$ & $\begin{array}{c}16 \mathrm{~h} \text { in } \\
\text { building }\end{array}$ & $\begin{array}{c}24 \mathrm{~h} \text { in } \\
\text { building }\end{array}$ & $\begin{array}{c}\text { Cows on pasture } \\
\text { from April 1986 }\end{array}$ & $\begin{array}{c}\text { Cows fed with } \\
\text { uncontaminated fodder }\end{array}$ \\
\hline Ecosys-87 & 1.76 & 1.41 & 1.06 & 3.48 & 0.84 \\
\hline LIETDOS & 0.93 & 0.53 & 0.23 & 3.49 & 0.55 \\
\hline OSCAAR & 0.81 & 0.72 & 0.63 & 3.8 & 0.01 \\
\hline UniVes & 0.66 & 0.58 & 0.44 & 0.53 & less than 0.01 \\
\hline CLRP & 0.79 & 0.7 & 0.53 & 0.64 & 0.03 \\
\hline CLIMRAD & 0.74 & 0.55 & 0.36 & 1.09 & 0.45 \\
\hline SCHRAADLO-T & 1.6 & 1.5 & 1.4 & 1.65 & 0.67 \\
\hline IRH-model & 0.81 & 0.72 & 0.63 & 6.27 & 0.19 \\
\hline Geommean & 0.95 & 0.77 & 0.57 & 1.91 & 5.6 \\
\hline Geom. S.D. & 1.4 & 1.5 & 1.7 & 2.3 & not calculated \\
\hline
\end{tabular}

\section{CONCLUSIONS}

The importance of the feed-back between model calculations and measured data is stressed by the results of different models calculations in this scenario. For emergency situations, it is important that models allow the input of measured data (contamination of grass, milk etc.) in different steps of the calculations. More over, measured data, including activity of radioiodine in thyroid, have to be collected in order to allow evaluation of the efficiency of countermeasures as early as possible. The emergency response preparedness requires realistic and validated dose assessment methodologies and an appreciation of likely uncertainties.

\section{Acknowledgments}

This work was supported in part by the intra-agency agreement between the Central Laboratory for Radiological Protection, Warsaw and the National Cancer Institute, NIAID Agreement no. 263-MQ- 408981 and NCI Agreement no. 263-MQ-408981. Preparation of the data for Prague Scenario was supported by project SUJB No3/2006.

\section{References}

[1] Wilhelmová, L., Tomášek M. and Rybáèek, K. Aerosol and gaseous radioiodine concentration in the air of Prague after the Chernobyl accident, J. Radioanal. Nucl. Chem., Letters 117 (50, 305309, 1987)

[2] Report on Radiation Situation in CSSR after Chernobyl Accident. Institute of Hygiene and Epidemiology, Centre of Radiation Hygiene, Prague, 1986

[3] Validation of models using Chernobyl fallout data from the Central Bohemia region of the Czech Republic, Scenario CB, First report of the VAMP Multiple Pathways Assessment Working Group, IAEA-TECDOC-795, IAEA, Vienna, April 1995

[4] Krajewski, P., Ammann, M., Bartusková, M., Duffa, C., Filistovic, V., Homma, T., Kanyár, B., Malátová, I., Nedveckaite, T., Simon, S., Vlasov, O., Webbe-Wood, D. and Zvonova, I.: Validation of dosimetry models and assessment of the countermeasures effectiveness using data from Chernobyl ${ }^{131}$ I releases, International Conference on Environmental Radioactivity: From Measurements and Assessments to Regulation, 23-27. April 2007, Vienna, Austria

[5] Likhtarev, I. A., Shandala, N. K., Gulko, G. M., et al. Ukrainian thyroid doses after the Chernobyl accident, Health Physics 64(6), 594-599, 1993).

[6] Pitkevich, V.A., Shershakov, V. M., Duba, V. V., et al. Reconstruction of composition of the Chernobyl radionuclide fallout in the territories of Russia. Radiation and Risk 3:62-93, 1993. (In Russian) 
